\title{
Enhanced protective properties and UV stability of epoxy/graphene nanocomposite coating on stainless steel
}

\author{
H. Alhumade ${ }^{1}$ A. Yu ${ }^{1}$, A. Elkamel ${ }^{1}$, L. Simon ${ }^{1}, A$. Abdala $^{2,3 *}$ \\ ${ }^{1}$ Department of Chemical Engineering, University of Waterloo, Waterloo, Ontario, Canada N2L 3G1 \\ ${ }^{2}$ Qatar Environmental and Energy Research Institute (QEERI), Hamad Bin Khalifa University, Qatar Foundation, Doha, \\ Qatar \\ ${ }^{3}$ College of Sciences and Engineering, Hamad Bin Khalifa University, Qatar Foundation, Doha, Qatar
}

Received 8 June 2016; accepted in revised form 26 July 2016

\begin{abstract}
Epoxy-Graphene (E/G) nanocomposites with different loading of graphene were prepared via in situ prepolymerization and evaluated as protective coating for Stainless Steel 304 (SS304). The prepolymer composites were spin coated on SS304 substrates and thermally cured. Transmission Electron Microscopy (TEM) and Scanning Electron Microscopy (SEM) were utilized to examine the dispersion of graphene in the epoxy matrix. Epoxy and E/G nanocomposites were characterized using X-ray diffraction (XRD) and Fourier Transform Infrared (FTIR) techniques and the thermal behavior of the prepared coatings is analyzed using Thermogravimetric analysis (TGA) and Differential scanning calorimetry (DSC). The corrosion protection properties of the prepared coatings were evaluated using Electrochemical Impedance Spectroscopy (EIS) and Cyclic Voltammetry (CV) measurements. In addition to corrosion mitigation properties, the long-term adhesion performance of the coatings was evaluated by measuring the adhesion of the coatings to the SS304 substrate after 60 days of exposure to $3.5 \mathrm{wt} \% \mathrm{NaCl}$ medium. The effects of graphene loading on the impact resistance, flexibility, and UV stability of the coating are analyzed and discussed. SEM was utilized to evaluate post adhesion and UV stability results. The results indicate that very low graphene loading up to $0.5 \mathrm{wt} \%$ significantly enhances the corrosion protection, UV stability, and impact resistance of epoxy coatings.
\end{abstract}

Keywords: nanocomposites, graphene, corrosion, coatings, adhesion

\section{Introduction}

Damage due to corrosion is one of the most common causes of metal component failures. The lack of mitigation protocols or methods of such electrochemical reactions may result in serious losses in both economy and industry. Although, total elimination of the corrosion process is not possible, there are different techniques that are utilized in various fields such as marine equipment, pipelines and construction in order to attenuate the intensity and severity of corrosion. Anodic or cathodic protection [1], corrosion inhibitors [2] and protective coatings [3] are examples of these techniques. Nevertheless, an increasing number of research studies have been devoted to develop more robust techniques to extend the life cycle of metals in various environments. An effective example of such technique is the use of nanocomposites, hydrophobic and organic-inorganic hybrid materials as anti-corrosion coatings in various corrosive environments [4-7].

Stainless steel already has remarkable corrosion resistance and is expected to perform satisfactorily in different environments. However, stainless steel is susceptible to pitting corrosion in chloride ions rich environments such as the marine atmospheric environment. Pitting corrosion is a galvanic corrosion

$\overline{{ }^{*} \text { Corresponding author, e-mail: aaabdalla@,qf.org.qa }}$

C BME-PT 
process where localized active areas are formed as a result of localized inclusions or breakdown of the protective passive film of chromium oxide. The presence of corrosion agents such as chloride, water and oxygen initiates localized dissolution that penetrates through the metal thickness. This penetration may not be detected until severe damages has occurred and therefore pitting corrosion is considered insidious and more difficult to detect, evaluate and mitigate compared to other more uniform corrosions. Therefore, additional means of corrosion protection are required to boost the life cycle of stainless steel substrates in chloride ions rich environment. Polymer based composites are perfect examples of protective coatings that can enhance various properties of the coated metal substrates including but not limited to corrosion resistance. A number of polymeric matrices have already been evaluated for corrosion protection purposes; however, the lack of interface adhesion foils the use of most of these polymeric matrices as anticorrosion coatings [8,9]. Epoxy is an environmental friendly polymeric matrix that combines various remarkable properties such as exceptional thermal stability and low thermal expansion coefficient. These desirable properties in addition to the noble interface adhesion of epoxy with various metal substrates trigger the investigation of epoxy as an anticorrosion coating on SS304 substrates.

The properties of the polymer matrix can be further enhanced by the incorporation of nanofillers. Clay and carbon nanotubes are examples of nanofillers that are incorporated in epoxy matrix to enhance the remarkable properties. However, the lower density, high surface area, and the very high aspect ratio attracted much attention to graphene [10] as a candidate for enhancing the corrosion protection property of epoxy. Graphene nanosheets, graphene nanoplatelets and functionalized graphene are different forms of graphene that have been utilized as fillers in various polymeric matrices to enhance their mechanical, thermal, dielectric, gas barrier, and corrosion resistance properties [11-22]. The incorporation of graphene into the epoxy matrix is expected to prolong the pathway corrosive agents follow to reach the metal substrate. This graphene barrier effect is expected to limit the diffusion of ions and water molecules and consequently extends the life cycle of the coated substrates. To the best of our knowledge, there is no study that investigates the application of epoxy/graphene composites as anticorrosion coating for stainless steel Type 304.

In this study, E/G nanocomposites are developed and used as protective coating for stainless steel. The corrosion protection property of the $\mathrm{E} / \mathrm{G}$ nanocomposite is evaluated by conducting electrochemical and weight loss measurements in $3.5 \mathrm{wt} \%$ Sodium Chloride aqueous solution. The study also examines the effect of graphene loading on the adhesion, impact resistance and flexibility of $\mathrm{E} / \mathrm{G}$ composite coatings. Furthermore, the long-term performance of the protective coatings is also examined by conducting the adhesion test after exposing the coated substrates to the $3.5 \mathrm{wt} \% \mathrm{NaCl}$ solution for 60 days. In addition, the influences of the incorporation of graphene on the thermal behavior as well as UV resistance of epoxy are evaluated.

\section{Experimental}

\subsection{Materials}

Polished SS304 sheet $99.9 \%$ purity (3254K91, McMASTER-CARR, Ohio, USA) was used as substrates., Bisphenol A diglycidyl ether (D3415, BADGE, Sigma Aldrich, Ontario, Canada) and Poly (propylene glycol) bis(2-aminopropyl ether) (406651, B230, Sigma Aldrich, Ontario, Canada) were used as received. Graphene nanosheets (GN1P0005, ACS Material, Massachusetts, USA) were synthesized by thermal exfoliation/reduction of graphite oxide, which was prepared using the modified Hummer method and it has a surface area of $400-1000 \mathrm{~m}^{2} / \mathrm{g}$ and electrical resistivity of $\leq 0.3 \Omega \cdot \mathrm{cm}$, as per the supplier specifications.

\subsection{Composite preparation, coating, and curing}

$\mathrm{E} / \mathrm{G}$ composites with graphene loading of $0.1 \mathrm{wt} \%$ $\left(\mathrm{E} / \mathrm{G}_{0.1}\right), 0.5 \mathrm{wt} \%\left(\mathrm{E} / \mathrm{G}_{0.5}\right)$ and $1 \mathrm{wt} \%\left(\mathrm{E} / \mathrm{G}_{1}\right)$ were prepared using in situ polymerization approach. The prepolymer|graphene mixture was then spin coated on SS304 substrate before thermal curing. Figure 1, schematically depicts the overall composite preparation, coating and curing process.

As an example, to prepare $\mathrm{E} / \mathrm{G}$ nanocomposite with $0.1 \mathrm{wt} \%$ graphene via situ prepolymerization, graphene $(2.1 \mathrm{mg})$ was dispersed in $0.5 \mathrm{~g}$ curing agent (hardener) B230 by stirring and bath sonication 


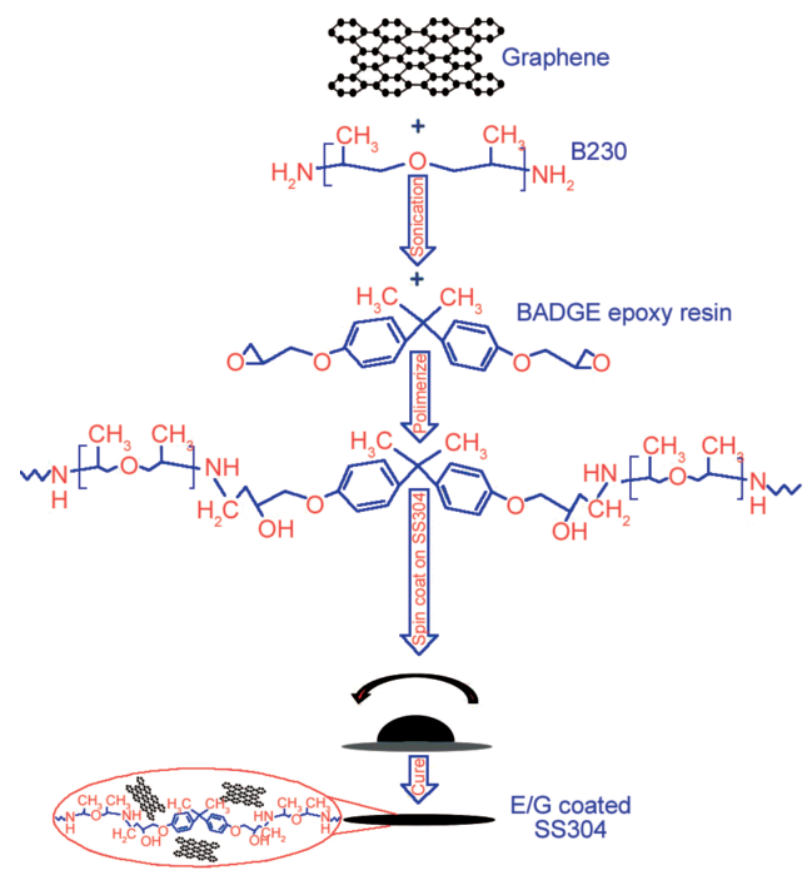

Figure 1. Schematic description of the process for the synthesis of $\mathrm{E} / \mathrm{G}$ composites using in situ polymerization

(FS30H, Fisher Scientific, Ontario, Canada) for an hour each. BADGE (1.5 g) was added to the graphene suspension and the mixture was stirred for $1 \mathrm{~h}$ followed by sonication for an additional hour. The mixture was homogenized (125, Fisher Scientific, Ontario, Canada) for $30 \mathrm{~min}$, sonicated for $5 \mathrm{~min}$ and spin coated (SC 100, Smart Coater, Missouri, USA) at 400 RPM for 1 min on a clean $\mathrm{SS} 304$ substrate. The composite was cured at $50^{\circ} \mathrm{C}$ for $4 \mathrm{~h}$ to obtain $124 \pm 2 \mu \mathrm{m}$ thick $\mathrm{E} / \mathrm{G}_{0.1}$ coated SS304 substrate. The same procedure was followed to prepare $\left(E / G_{0.5}\right)$ and $\left(\mathrm{E} / \mathrm{G}_{1}\right)$ using 10.1 and $20.3 \mathrm{mg}$ of graphene, respectively.

\subsection{Composite characterization}

The dispersion of graphene in the epoxy matrix was examined using TEM (Philips CM-10 TEM, Geneva, Switzerland). Samples for the TEM study were prepared by scraping the $\mathrm{E} / \mathrm{G}$ coating with a sharp knife and the collected $\mathrm{E} / \mathrm{G}$ composite was dispersed in methanol for $5 \mathrm{~min}$. The sample was then fished using TEM copper grid and allowed to dry under vacuum at room temperature. FTIR (Tensor 27, Bruker, Massachusetts, USA) was used to acquire spectra of epoxy and E/G composites at room temperature. XRD diffraction patterns of epoxy and $\mathrm{E} / \mathrm{G}$ composites are recorded in the range of $2 \theta=3$ to $90^{\circ}$ at $0.24^{\circ} / \mathrm{min}$ scan rate and $0.02^{\circ}$ step size using MiniFlex 600 (Rigaku, Beijing, China).

\subsection{Adhesion test}

The interfacial adhesion between the coating and the SS304 substrate was measured according to the ASTM-D3359 standard using an adhesion tape kit (PA-2000, Paul N. Gardner Company Inc., Florida, USA) with standard blade (11-teeth with teeth spacing of $1 \mathrm{~mm}$ ). The Interface adhesion was evaluated before and after exposing the coating to the $3.5 \mathrm{wt} \%$ $\mathrm{NaCl}$ solution for 60 days in order to examine the long-term durability of the coatings. Post-adhesion tests results were captured using SEM (Zeiss LEO 1550, New York, USA). SEM samples were placed on carbon tape attached to the SEM holder and the sample was further coated with gold via sputtering for $120 \mathrm{~s}$.

\subsection{Gravimetric analysis}

The weight loss measurements were conducted in $500 \mathrm{~mL}$ glass beaker placed in a temperature controlled water bath. Coated and uncoated SS304 substrates were weighted, placed in Teflon holders with $1 \mathrm{~cm}^{2}$ exposed surface area and immersed in a $3.5 \mathrm{wt} \% \mathrm{NaCl}$ solution for 60 days at $25^{\circ} \mathrm{C}$. At the end of the exposure period, the samples were removed and washed with double distilled water before a fine brush was used to strip off the corrosion products. The samples were cleaned again by bath sonication in a double distilled water for $10 \mathrm{~min}$ to ensure the removal of corrosion residues, dried and weighted. All mass loss measurements were carried out in triplicate and the mean weight and the standard deviation are reported.

\subsection{Electrochemical measurements}

Electrochemical measurements were conducted at $25^{\circ} \mathrm{C}$ in a double-jacketed $1 \mathrm{~L}$ corrosion cell covered with a drilled Teflon plate to allow electrodes immersion. A three electrode configuration was used to conduct the measurements, where a Silver/Silver Chloride ( $\mathrm{Ag} / \mathrm{AgCl})$ electrode was used as the reference electrode (RE), two graphite rods as the auxiliary electrodes (AE) and a $1 \mathrm{~cm}^{2}$ coated/uncoated SS304 substrate as the working electrode (WE). The WE was washed with acetone and double distilled water, dried and then installed in the sample holder 
before conducting the tests. $1 \mathrm{~L}$ temperature controlled $3.5 \mathrm{wt} \% \mathrm{NaCl}$ solution was used as the electrolyte. EC-Lab software (Bio-Logic) and VSP-300 workstation (Uniscan instruments Ltd., Claix, France) were used to conduct all electrochemical measurements, where each measurement was repeated three times in order to confirm the reproducibility of the collected raw data.

The potential of the WE was allowed to stabilize for 30 min before conducting the EIS followed by the potentiodynamic measurements. The EIS measurements were conducted at frequency range from $200 \mathrm{kHz}$ to $100 \mathrm{mHz}$ to generate Bode and Nyquist plots. Furthermore, an equivalent circuit was used to fit the raw impedance data and EC-Lab software was used to evaluate the different components of the equivalent circuits. The potentiodynamic measurements were conducted by scanning the potential of the WE from -500 to $500 \mathrm{mV}$ at a rate of $20 \mathrm{mV} / \mathrm{min}$ to produce the Tafel plots. These plots were used to extract the corrosion current $\left(I_{\text {corr }}\right)$ using EC-Lab software by extrapolating the linear portion of the anodic and the cathodic curves.

\subsection{Thermal behavior and $U V$ degradation}

The thermal stability of the nanocomposite coatings was evaluated using thermal gravimetric analysis (TGA) (TA instruments, Q500, Ontario, Canada) in the temperature range $25-800^{\circ} \mathrm{C}$, while the glass transition temperature was observed using differential scanning calorimetry (DSC) (TA instruments, Q2000, Ontario, Canada) in the temperature range $25-200^{\circ} \mathrm{C}$ at $10^{\circ} \mathrm{C} / \mathrm{min}$ heating rate.

The Resistance of the prepared Epoxy and E/G coatings to UV degradation was assessed using an accelerated weathering tester (QUV, Q-LAB, Florida, USA) according to ASTM-D4587 standard. Testing specimens were continuously exposed to repeated UV cycle at $60 \pm 2.5^{\circ} \mathrm{C}$ for 8 hours, followed by a condensation cycle at $50 \pm 2.5^{\circ} \mathrm{C}$ for 4 hours over 30 days followed by SEM examination of the surface morphology of the epoxy and E/G coatings.

\subsection{Flexibility and impact resistance}

Two different types of tests were carried out to illustrate the influences of graphene loading on the room temperature flexibility and impact resistance of the coatings. In the bending test, the coated substrate was bent over a conical shaped mandrel (MN-301003, Paul N. Gardner Company Inc., Florida, USA) with a diameter ranges from 3.1 to $38 \mathrm{~mm}$ to assess the flexibility of the coatings. The test was repeated three times and the mean diameter at which the coatings cracked were reported.

Impact resistance was performed to evaluate the resistance of the prepared coatings to rapid deformation by a falling weight. The test was conducted using a universal impact tester (IM-172RF, Paul N. Gardner Company Inc., Florida, USA) with combined 0.5 inch ball and $2 \mathrm{lb}$ weight indenter according to ASTM D2794 standard. The combined weight and indenter were raised 1 inch in the testing tube and released to drop on the coated substrate and the falling weight test was repeated with 1 inch increments in height until a crack in the coating was observed. The height at which the coating cracks was recorded and the test was repeated slightly above, slightly below and at the recorded height five times each according to the ASTM standard. The elevation at which the coating cracks in all five trials is reported as the impact resistance limit of the coating to rapid deformation.

\section{Results and discussion}

\subsection{Characterization of the $E / G$ composites}

The dispersion of graphene in the polymeric matrix for $\mathrm{E} / \mathrm{G}_{0.1}$ and $\mathrm{E} / \mathrm{G}_{0.5}$ composites was examined using SEM and TEM as shown in Figure 2. The TEM images, clearly illustrate the influence of graphene loading on the degree of dispersion, where graphene is well dispersed as indicated by thin sheets in the $\mathrm{E} / \mathrm{G}_{0.1}$ coating, while thick stack of graphene sheets were observed in $\mathrm{E} / \mathrm{G}_{0.5}$ coating. SEM images, depicts wide degrees of dispersion in both $\mathrm{E} / \mathrm{G}_{0.1}$ and $\mathrm{E} / \mathrm{G}_{0.5}$ composites.

FTIR was utilized to characterize both epoxy and E/G composites as depicted in Figure 3. Different characteristic peaks are identified, such as the peaks at 1508 and $1609 \mathrm{~cm}^{-1}$ (C-C skeletal stretching), $915 \mathrm{~cm}^{-1}$ (epoxide ring) and $3380 \mathrm{~cm}^{-1}$ (-OH stretching), which confirms the curing of the epoxy resin. Comparing the epoxy spectrum to the $\mathrm{E} / \mathrm{G}$ composite spectra revealed that there were no clear dissimilar absorption peaks indicating no chemical linkages between graphene and the epoxy function groups. Epoxy and E/G composites were also characterized 

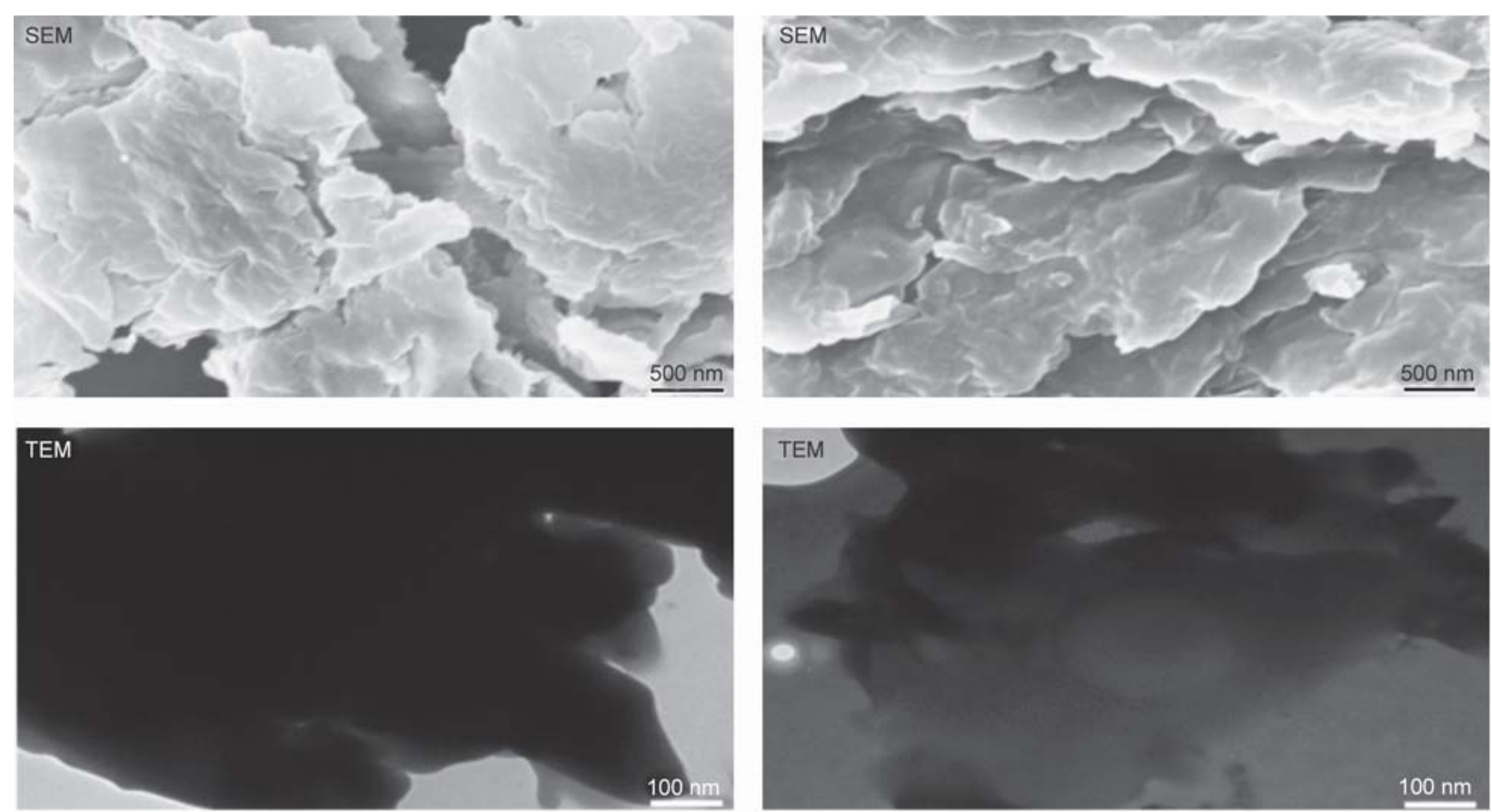

a)

b)

Figure 2. SEM and TEM images for graphene dispersion in (a) $E / G_{0.5}$ and (b) $E / G_{0.1}$

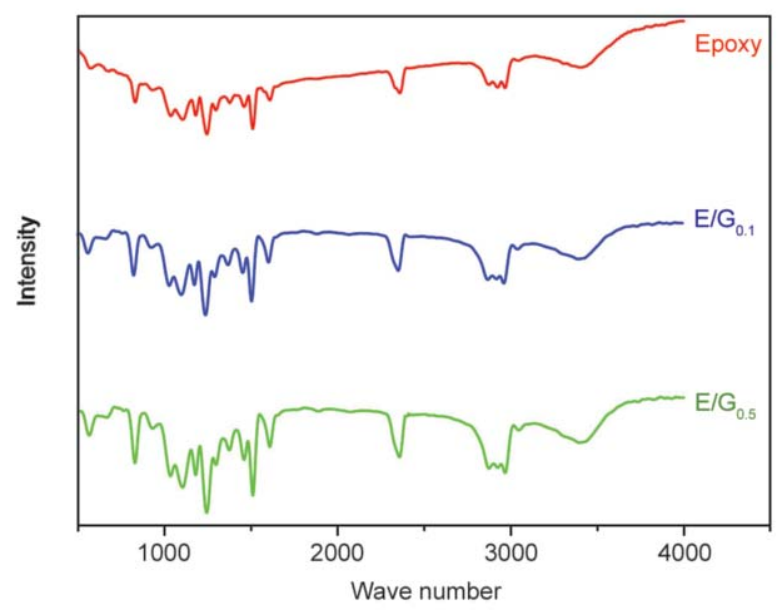

Figure 3. FTIR spectra of neat epoxy and E/G composites

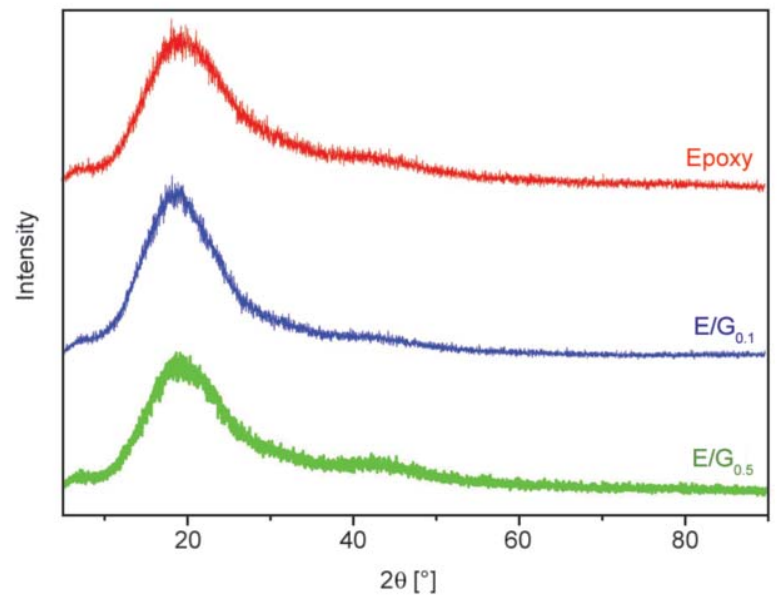

Figure 4. XRD patterns of neat epoxy and $\mathrm{E} / \mathrm{G}$ composites using XRD and the diffraction spectrum are depicted in Figure 4. All XRD patterns show broadly amorphous peak appearing around $2 \theta$ value between 10 and $30^{\circ}$, which ascribed to the homogeneously amorphous of epoxy. Moreover, the observed XRD patterns indicate that the degree of crystallinity of epoxy is retained after incorporation of graphene.

\subsection{Adhesion test}

Interface adhesion between the metal substrate and the coating is a significant property that needs to be examined before the coating can be considered protective. Poor interface adhesion may result in the formation of voids between the metal substrate and the coating, where corrosive agents may accumulate and accelerate the corrosion process. Therefore, decent interface adhesion is always desired. The adhesion of E/G coatings to the $\mathrm{SS} 304$ substrates were examined and evaluated according to ASTM D3359 adhesion tape standard test. The test was performed on $\mathrm{E} / \mathrm{G}_{0.1}$ and $\mathrm{E} / \mathrm{G}_{0.5}$ coatings before and after 60 days of exposure to the $3.5 \mathrm{wt} \% \mathrm{NaCl}$ solution. The post adhesion test results are presented in Figure 5, where no peelings were observed in any of the coatings and all coatings received $5 \mathrm{~B}$ rating $(0 \%$ peeling) according to the ASTM standard.

Moreover, it was interesting to observe the shortcoming of increasing the load of graphene beyond 

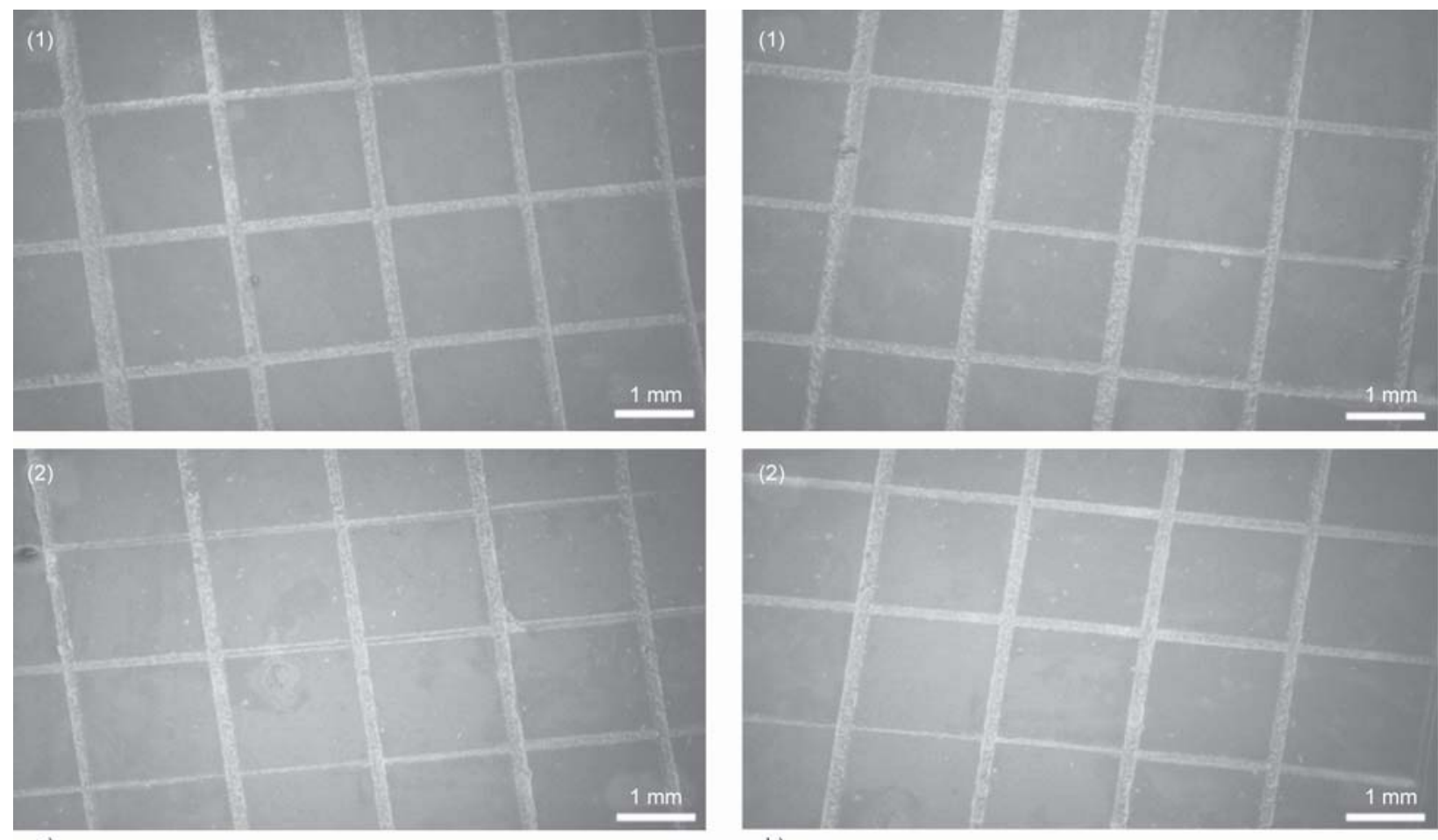

a)

b)

Figure 5. SEM images of post-adhesion tests of (1) E/G $\mathrm{G}_{0.1}$ and (2) $\mathrm{E} / \mathrm{G}_{0.5}$ coated SS304 substrates (a) before and (b) after 60 days of exposure to the corrosive medium

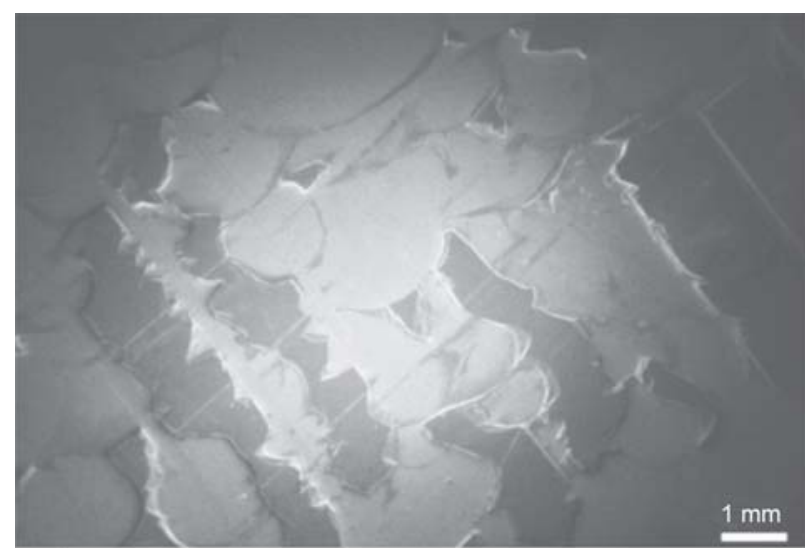

a)

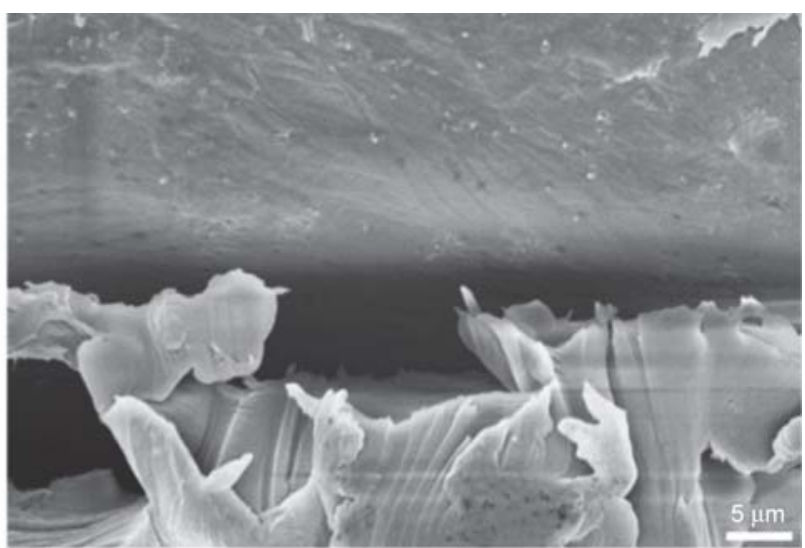

b)

Figure 6. SEM image of (a) post-adhesion test and (b) cross section view of $\mathrm{E} / \mathrm{G}_{1}$ coated $\mathrm{SS} 304$ substrate

the percolation loading. The disadvantage of increasing the graphene loading is clearly depicted in Figure $6 \mathrm{a}$, where poor interface adhesion between the $\mathrm{E} / \mathrm{G}_{1}$ coating and SS304 substrate was observed and the coating receives $0 \mathrm{~B}$ rate (more than $65 \%$ peeling) according to the ASTM standard. The observed undesirable influence of the load of graphene on the interface adhesion can be attributed to accumulation of graphene at the interface, which attenuates the contact area between epoxy resin and SS304 substrate as depicted in Figure 6b, where clear gaps can be observed between $\mathrm{E} / \mathrm{G}_{1}$ and the $\mathrm{SS} 304$ substrate.

\subsection{Weight loss}

Weight loss measurements for coated/uncoated SS304 substrate were reported after 60 days of immersion in the $3.5 \mathrm{wt} \% \mathrm{NaCl}$ solution at $25^{\circ} \mathrm{C}$. These measurements were used to calculate the corrosion rate $\left(R_{\text {corr }}\right)$ and the protection efficiency $\left(P_{\mathrm{EF}}\right)$ of the different coatings using Equtions (1) and (2):

$R_{\mathrm{corr}}=\frac{W_{0}-W}{A \cdot t}$

$P_{\mathrm{EF}}[\%]=\left(1-\frac{R_{\text {corr }}}{R_{\text {corr }}^{\circ}}\right) \cdot 100$ 
Table 1. Weight loss measurements for bare SS304, epoxy, $\mathrm{E} / \mathrm{G}_{0.1}$ and $\mathrm{E} / \mathrm{G}_{0.5}$ coated $\mathrm{SS} 304$ in a $3.5 \mathrm{wt} \% \mathrm{NaCl}$ solution

\begin{tabular}{|c|c|c|c|c|c|}
\hline Sample & $\begin{array}{c}W_{0} \\
{[\mathrm{mg}]}\end{array}$ & $\begin{array}{c}W \\
{[\mathrm{mg}]}\end{array}$ & $\begin{array}{c}R_{\text {corr }} \\
{\left[\mathrm{mg} \cdot \mathrm{cm}^{-2} \cdot \mathrm{d}^{-1}\right]}\end{array}$ & $\begin{array}{c}R_{\text {corr, STD }} \\
{\left[\mathrm{mg} \cdot \mathrm{cm}^{-2} \cdot \mathrm{d}^{-1}\right]}\end{array}$ & $\begin{array}{l}P_{\text {EF }} \\
{[\%]}\end{array}$ \\
\hline SS304 & 93.1 & 66.9 & 0.440 & 0.009 & - \\
\hline Epoxy & 107.0 & 101.6 & 0.090 & 0.011 & 79.5 \\
\hline $\mathrm{E} / \mathrm{G}_{0.1}$ & 115.9 & 113.5 & 0.040 & 0.008 & 90.9 \\
\hline $\mathrm{E} / \mathrm{G}_{0.5}$ & 122.9 & 122.0 & 0.015 & 0.005 & 96.6 \\
\hline
\end{tabular}

where $A$ is the exposed surface area $\left(1 \mathrm{~cm}^{2}\right), W_{0}$ and $W$ are the weight [mg] before and after exposure, respectively, $t$ is the immersion time (60 days), $R_{\text {corr }}$ and $R_{\text {corr }}^{\circ}$ are the corrosion rate of coated and bare SS304 substrates, respectively. Furthermore, standard deviation of $R_{\text {corr }}\left(R_{\text {corr, STD }}\right)$ was computed and reported in Table 1 using triplicate weight loss measurements for each sample.

The data reported in Table 1 illustrate that coating SS304 with epoxy may prolong the life cycle of the metal substrate as indicated by the decrease in the corrosion rate. Furthermore, the results demonstrate that the corrosion rate is attenuated and the protection efficiency of epoxy is enhanced by the incorporation of graphene. Moreover, the low values of Rcorr, STD demonstrate the excellent reproducibility of the results.

\subsection{Electrochemical impedance measurements}

EIS is a widely used technique to investigate electrochemical activity on metal substrates. Here, EIS is utilized to examine the corrosion behavior of bare and coated SS304 substrates. In EIS, an alternating current (AC) is forced through a circuit that may contain insulators, resistors and capacitors or combinations of items resulting in a complex output resistance known as impedance. In corrosion studies, the $\mathrm{AC}$ is fed to the system over a range of frequency and the complex output at different frequencies are reported as the impedance of the WE. Furthermore, impedance can be modelled using an equivalent circuit that contain a specific combination of different elements such as resistors and capacitors.

The impedance behavior of bare and coated SS304 substrates is measured in temperature controlled $3.5 \mathrm{wt} \% \mathrm{NaCl}$ electrolyte using the EC-Lab software after allowing the potential of the WE to stabilize for $30 \mathrm{~min}$. The EC-Lab software was also used to model

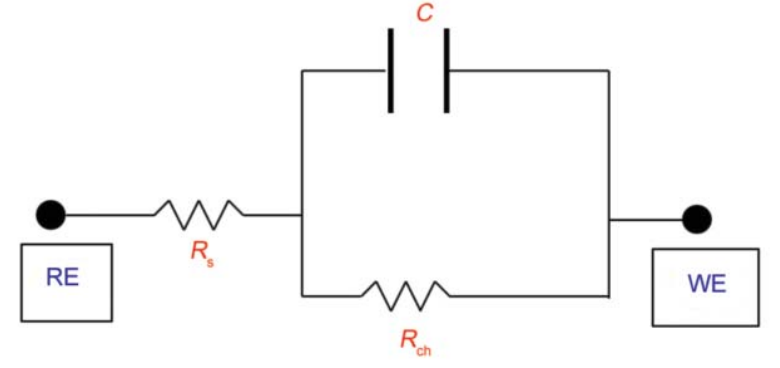

Figure 7. Equivalent circuits used to model the electrochemical impedance data

and fit the raw impedance data using equivalent circuits with specific combinations as shown in Figure 7. In the equivalent circuits, $R_{\mathrm{S}}$ and $R_{\mathrm{ch}}$ represent electrolyte and charge transfer resistances, respectively, while $C$ is a double layer capacitor. The magnitudes of the various elements in the equivalent circuit and the frequency of the AC signal $(\omega)$ were utilized to fit raw impedance data using Equation (3):

$$
\begin{aligned}
Z & =Z^{\prime}+j Z^{\prime \prime}= \\
& =R_{\mathrm{s}} \frac{R_{\mathrm{ch}}}{1+\left(R_{\mathrm{ch}} \cdot C \cdot \omega\right)^{2}}+j \frac{R_{\mathrm{ch}}^{2} \cdot C \cdot \omega}{1+\left(R_{\mathrm{ch}} \cdot C \cdot \omega\right)^{2}}
\end{aligned}
$$

Figure 8, depicts Nyquist plots for bare and coated SS304 substrate, where real and imaginary parts of the impedance are presented. The Nyquist plot clearly represents the corrosion protection by the epoxy coating as demonstrated by the increase in the size of the impedance semi-circleindicating annenhancementt in corrosion mitigation and slower corrosion rate for the epoxy coated sample compared to the bare SS304. Nevertheless, this corrosion protection enhancement is further improved by incorporating graphene in the epoxy matrix, where the real resistivity value at the high frequency end has increased

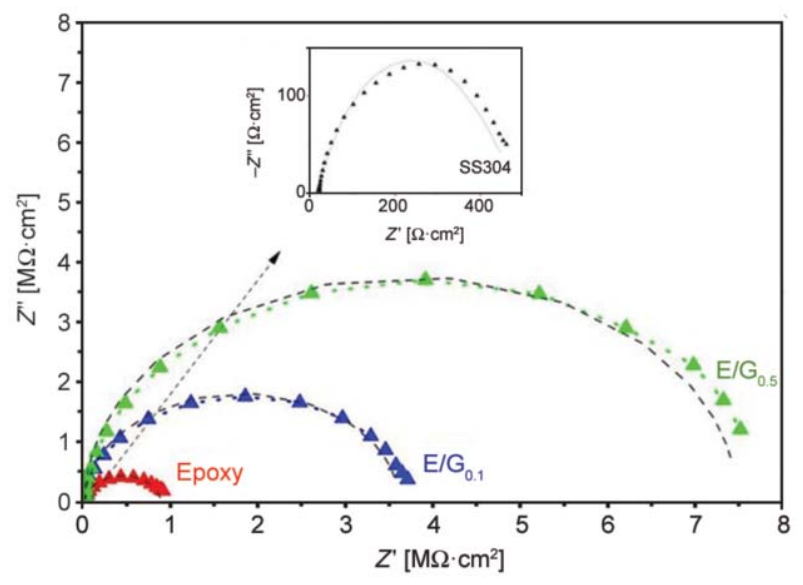

Figure 8. Nyquist plots for bare $\mathrm{SS} 304$ (inset), epoxy, $\mathrm{E} / \mathrm{G}_{0.1}$ and $\mathrm{E} / \mathrm{G}_{0.5}$ coated $\mathrm{SS} 304$ substrates 
from $1.0 \cdot 10^{6} \Omega \cdot \mathrm{cm}^{2}$ for the epoxy coated sample to $3.8 \cdot 10^{6} \Omega \cdot \mathrm{cm}^{2}$ for $E / \mathrm{G}_{0.1}$ coated sample and $7.8 \cdot 10^{6} \Omega \cdot \mathrm{cm}^{2}$ for $\mathrm{E} / \mathrm{G}_{0.5}$ coated sample.

In addition to the qualitative analysis, the computed values of the different elements of the equivalent circuits shown in Figure 7 can be used to evaluate the corrosion protection properties of the different coatings. It should be noted that the unique combinations of elements in the presented circuits resulted in the best fitting of raw impedance data. Table 2, represents the values of the various elements in the equivalent circuits and the repeatability of triplicate measurements is illustrated by the small values of $R_{\mathrm{ch} \text {, STD }}$. The results clearly illustrate the ability of the epoxy coating to protect the SS304 substrate from corro-

Table 2. Electrochemical corrosion parameters obtained from equivalent circuit for EIS raw measurements for bare $\mathrm{SS} 304$, epoxy, $\mathrm{E} / \mathrm{G}_{0.1}$ and $\mathrm{E} / \mathrm{G}_{0.5}$ coated $\mathrm{SS} 304$ in $3.5 \mathrm{wt} \% \mathrm{NaCl}$ solution

\begin{tabular}{|l|c|c|c|c|}
\hline \multicolumn{1}{|c|}{ Sample } & $\begin{array}{c}\boldsymbol{R}_{\mathbf{S}} \\
{\left[\mathbf{\Omega} \cdot \mathbf{c m}^{2}\right]}\end{array}$ & $\begin{array}{c}\boldsymbol{C} \\
{[\mathbf{F}]}\end{array}$ & $\begin{array}{c}\boldsymbol{R}_{\mathbf{c h}} \\
{\left[\mathbf{\Omega} \cdot \mathbf{c m}^{2}\right]}\end{array}$ & $\begin{array}{c}\boldsymbol{R}_{\mathbf{c h}, \mathbf{S T D}} \\
{\left[\mathbf{\Omega} \cdot \mathbf{c m}^{2}\right]}\end{array}$ \\
\hline $\mathrm{SS} 304$ & 18.5 & $8.5 \cdot 10^{-6}$ & 450.5 & 10 \\
\hline Epoxy & 18.0 & $1.4 \cdot 10^{-10}$ & $8.7 \cdot 10^{5}$ & 190 \\
\hline $\mathrm{E} / \mathrm{G}_{0.1}$ & 18.2 & $3.9 \cdot 10^{-11}$ & $3.63 \cdot 10^{6}$ & 380 \\
\hline $\mathrm{E} / \mathrm{G}_{0.5}$ & 18.1 & $3.9 \cdot 10^{-11}$ & $7.55 \cdot 10^{6}$ & 260 \\
\hline
\end{tabular}

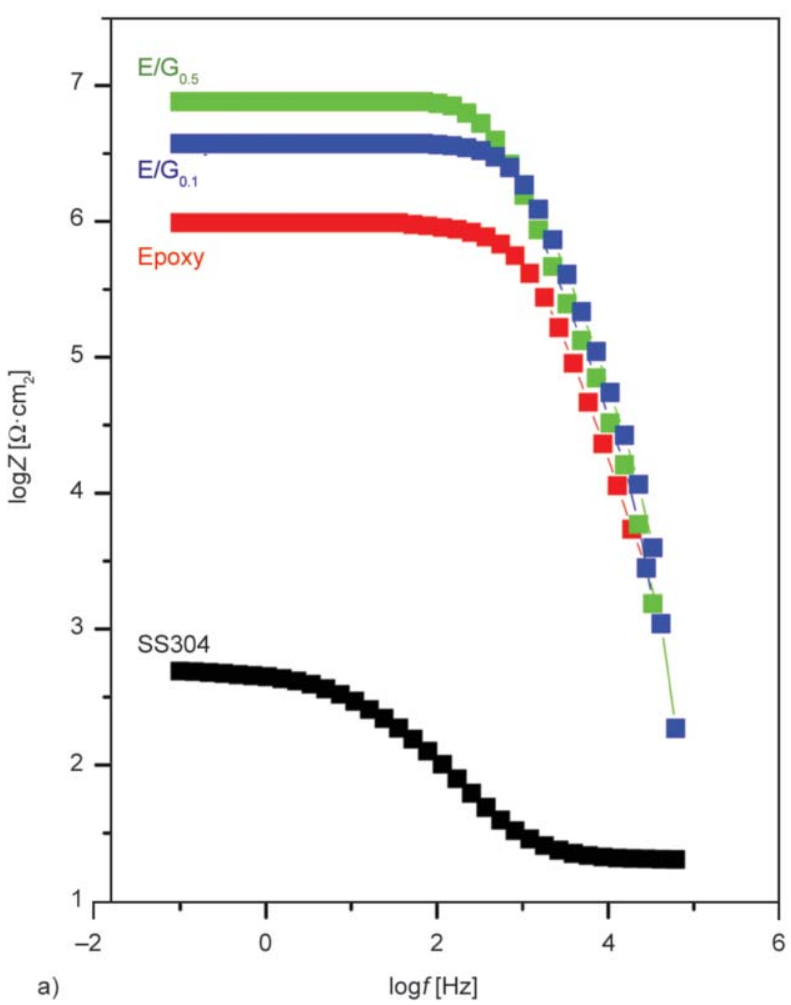

sion as indicated by the increase in the charge transfer resistance. Moreover, the results illustrate the advantages of incorporating graphene as implied by the significant increase in the charge transfer resistance for $\mathrm{E} / \mathrm{G}_{0.1}$ and $\mathrm{E} / \mathrm{G}_{0.5}$.

Bode plots are another representation of the corrosion protection ability of the coating. Figure $9 \mathrm{a}$, depicts the Bode plots, where the real part of impedance $\left(Z_{\text {real }}\right)$ is plotted versus frequency, while Figure $9 \mathrm{~b}$ depicts the phase plots. Corrosion resistance can also be represented by the $Z_{\text {real }}$ values at the lowest recorded frequencies. From Figure $9 \mathrm{a}, \log Z_{\text {real }}$ at the lowest frequencies for bare, epoxy, $\mathrm{E} / \mathrm{G}_{0.1}$ and $\mathrm{E} / \mathrm{G}_{0.5}$ coated SS304 are 2.7, 6.0, 6.6 and $6.9 \Omega \cdot \mathrm{cm}^{2}$, respectively.

EIS results illustrate that epoxy coatings may mitigate the corrosion process on SS304 substrate and prolong the life cycle of the metal. However, the incorporation of graphene would further enhance such a protection characteristic of the epoxy and the degree of enhancement depends on graphene loading. This variation in protection efficiencies can be attributed to the noble barrier property of graphene [16], which attenuate the corrosion rate by prolonging the tortuosity pathway for the corrosive agents to reach the SS304 substrate.

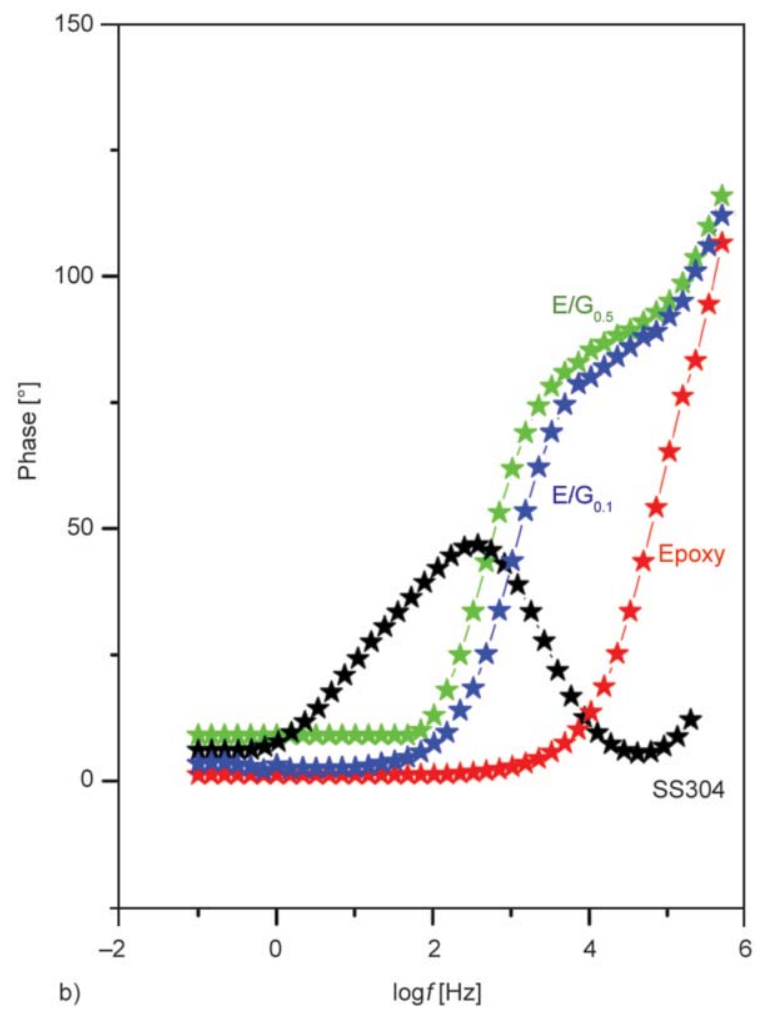

Figure 9. (a) Bode and (b) phase plots for bare $\mathrm{SS} 304$, epoxy, $\mathrm{E} / \mathrm{G}_{0.1}$ and $\mathrm{E} / \mathrm{G}_{0.5}$ coated $\mathrm{SS} 304$ substrates 


\subsection{Potentiodynamic measurements}

Cyclic Voltammetry is a widely utilized technique to characterize electrochemical behavior of metal substrates and coatings. In this study, a three-electrode configuration was used to conduct cyclic voltammetry tests on bare and coated SS304 substrates. The raw data were recorded using the EC-Lab software and all measurements were obtained in $3.5 \mathrm{wt} \% \mathrm{NaCl}$ solution at $25^{\circ} \mathrm{C}$. Furthermore, the potential of the testing sample was allowed to stabilize for $30 \mathrm{~min}$ before conducting any experiment. Even though the potential of the working electrode was scanned from -500 to $500 \mathrm{mV}$, only the areas where the electrode shifted from the anodic to cathodic behavior, which is known as the Tafel plots, were presented as shown in Figure 10. Important parameters such as $E_{\text {corr }}$ and $I_{\text {corr }}$ were extracted from the Tafel plots. Furthermore, the extracted $E_{\text {corr }}$ and $I_{\text {corr }}$ from triplicates measurement for each sample were utilized to demonstrate the reproducibility of the results by analysis of the standard deviation of $E_{\text {corr }}\left(E_{\text {corr, STD }}\right)$ and $I_{\text {corr }}$ $\left(I_{\text {corr }}, \mathrm{STD}\right)$, which are reported in Table 3.

These extracted parameters can be used to compute the polarization resistances $\left(R_{\mathrm{p}}\right)$ of the protective coatings using Equation (4), which is known as the Stern-Geary equation:

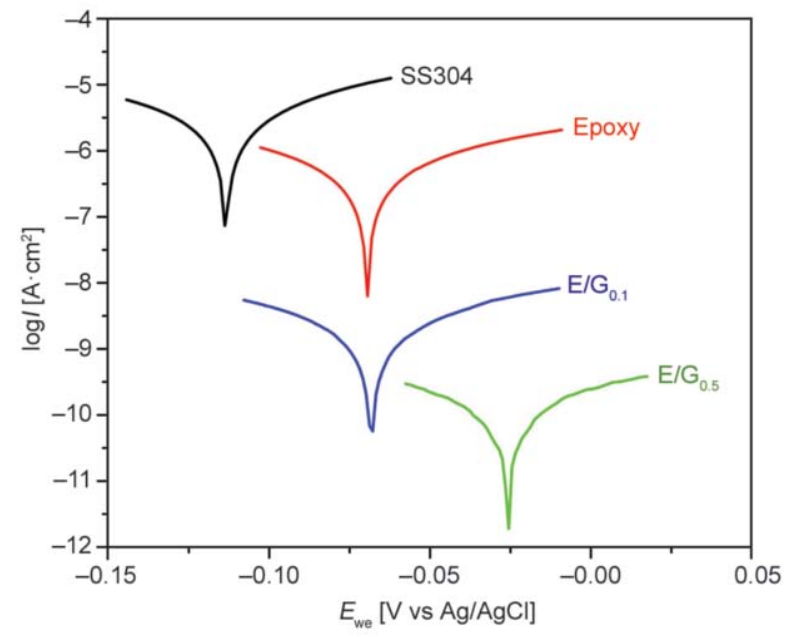

Figure 10. Tafel plots for bare SS304, epoxy, E/G $\mathrm{G}_{0.1}$ and $\mathrm{E} / \mathrm{G}_{0.5}$ coated $\mathrm{SS} 304$ substrates
$R_{\mathrm{p}}=\frac{b_{\mathrm{a}} \cdot b_{\mathrm{c}}}{2.303\left(b_{\mathrm{a}}+b_{\mathrm{c}}\right)} \cdot I_{\text {corr }}$

where $b_{\mathrm{a}} / b_{\mathrm{c}}$ are the anodic/cathodic Tafel slops $(\mathrm{d} E / \mathrm{d} \log I)$, respectively, and extrapolating the linear portion of these curves determines $I_{\text {corr }}$ at the intersection. Finally, $I_{\text {corr }}$ values can be used to evaluate the protection efficiencies of the different coatings using Equation (5):

$P_{\mathrm{EF}}[\%]=\left(1-\frac{I_{\text {corr }}}{I_{\text {corr }}^{\circ}}\right) \cdot 100$

where $I_{\text {corr }}^{\circ}$ and $I_{\text {corr }}$ are corrosion currents of bare and coated SS304, respectively. The variations in corrosion and computed parameters $\left(E_{\text {corr }}, I_{\text {corr }}, R_{\mathrm{p}}\right)$, which are reported in Table 3 may explain the influences of the various protective coatings on the electrochemical behavior of the SS304 substrate. In general, a positive shift in $E_{\text {corr, }}, R_{\mathrm{p}}$ and $P_{\mathrm{EF}}$ plus a drop in $I_{\text {corr }}$, represents an enhancement in corrosion mitigation.

The abilities of $\mathrm{E} / \mathrm{G}$ coatings in mitigating corrosion on SS304 substrates were confirmed by the results presented in Figure 10 and Table 3. These results demonstrate that the corrosion protection performance of epoxy coatings can be significantly enhanced by the incorporation of graphene as illustrated by the positive shifts in the $E_{\text {corr, }}, R_{\mathrm{p}}$ and $P_{\mathrm{EF}}$ and the attenuation of the $I_{\text {corr }}$. Furthermore, it was interesting to observe that the level of enhancement in $P_{\mathrm{EF}}$ of E/G can be positively influenced by increasing the graphene loading as illustrated in Figure 10 and Table 3, which is in agreement with the results obtained from the gravimetric method. This enhancement in corrosion mitigation properties of $\mathrm{E} / \mathrm{G}$ coatings can again be attributed to the barrier property of graphene, which prolong the pathway that corrosive agents follow to reach the metal substrate.

\subsection{Thermal behavior and UV degradation}

The incorporation of graphene in polymeric matrix has influenced the thermal stability of the resin. This

Table 3. Electrochemical corrosion parameters obtained from cyclic voltammetry measurements for bare SS304, epoxy, $\mathrm{E} / \mathrm{G}_{0.1}$ and $\mathrm{E} / \mathrm{G}_{0.5}$ coated $\mathrm{SS} 304$ in a $3.5 \mathrm{wt} \% \mathrm{NaCl}$ solution

\begin{tabular}{|c|c|c|c|c|c|c|c|c|}
\hline Sample & $\begin{array}{c}E_{\text {corr }} \\
{[\mathrm{mV} \text { vs Ag/AgCl] }}\end{array}$ & $\begin{array}{c}E_{\text {corr, STD }} \\
{[\text { V vs Ag/AgCl] }}\end{array}$ & $\begin{array}{c}I_{\text {corr }} \\
{\left[\mu \mathrm{A} / \mathbf{c m}^{2}\right]}\end{array}$ & $\begin{array}{c}I_{\text {corr, }} \mathrm{STD} \\
{\left[\mu \mathrm{A} / \mathbf{c m}^{2}\right]}\end{array}$ & $b_{\mathrm{a}}$ & $b_{\mathrm{c}}$ & $\begin{array}{c}R_{\mathrm{P}} \\
{\left[\Omega \cdot \mathrm{cm}^{2}\right]}\end{array}$ & $\begin{array}{l}P_{\text {EF }} \\
{[\%]}\end{array}$ \\
\hline SS304 & -113.5 & 0.009 & 2.40 & 0.002 & 48.2 & 55.3 & 4.6 & - \\
\hline Epoxy & -69.4 & 0.060 & 0.46 & 0.010 & 87.0 & 88.2 & 41.3 & 80.8 \\
\hline $\mathrm{E} / \mathrm{G}_{0.1}$ & -65.0 & 0.010 & 0.06 & 0.009 & 82.3 & 74.0 & 282.0 & 97.5 \\
\hline $\mathrm{E} / \mathrm{G}_{0.5}$ & -27.7 & 0.007 & $8.7 \cdot 10^{-3}$ & 0.005 & 61.4 & 54.5 & 1441.0 & 99.6 \\
\hline
\end{tabular}




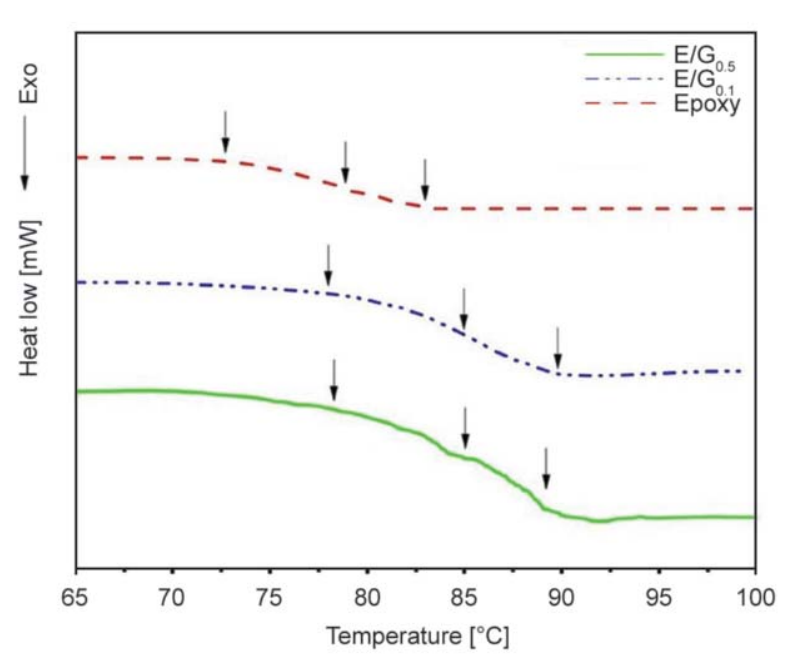

Figure 11. DSC thermograms of epoxy and $\mathrm{E} / \mathrm{G}$ coatings. The three arrow on each curve represent, from left to right, the onset, mid, and end point of the $T_{\mathrm{g}}$ transition.

can be observed as an upward shift in the glass transition temperature $\left(T_{\mathrm{g}}\right)$ as depicted in Figure 11. The increase in $T_{\mathrm{g}}$ has been reported for other graphene polymer nanocomposites and is attributed to the strong interface between the filler and polymer matrix, which restricts the polymer chains' mobility [23]. Moreover, incorporation of graphene increases the thermal stability of the epoxy composite as observed by the increase in onset degradation temperature ( $T_{\text {onset }}$ ), which is the temperature where $5 \%$ weight loss is observed as depicted in Figure 12, inset has increased from $352.8^{\circ} \mathrm{C}$ for the neat epoxy to 358.5 and $358.8^{\circ} \mathrm{C}$ for $\mathrm{E} / \mathrm{G}_{0.1}$ and $\mathrm{E} / \mathrm{G}_{0.5}$, respectively, confirming the strong interactions between graphene and epoxy polymer possibility through the amine groups on the polymer chains and the epoxy/hydrox$y l$ groups on the reduced graphene surface.

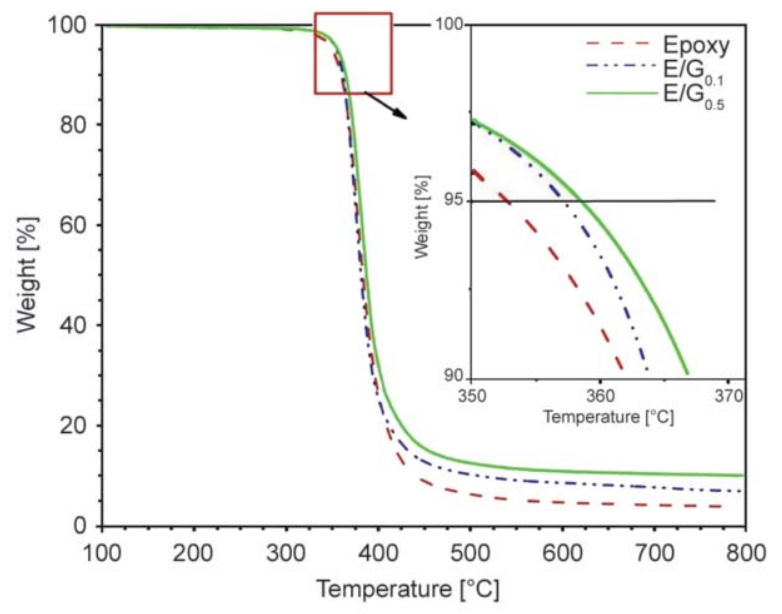

Figure 12. TGA thermograms of epoxy and E/G composites
Epoxy polymers are known to degrade when exposed to UV radiation [24]. Therefore, the surface morphology of the prepared coatings were observed after 30 days of exposure to UV and condensation cycles using SEM and results are depicted in Figure 13. Sever damages can be observed on the epoxy surface, where the damages were manifested in forms of micro-cracks and pits as illustrated in Figure 13a. Surface cracking was also observed on $\mathrm{E} / \mathrm{G}_{0.1}$ coating as depicted in Figure 13b; however, no evidence of pitting was observed. The capacity of graphene in enhancing the durability of the epoxy coating is well illustrated in Figure 13c, where increasing the load of graphene to $0.5 \%, \mathrm{E} / \mathrm{G}_{0.5}$, leads to prevention of pitting as well as significant reduction in the number of observed micro-cracks due to the enhanced UV stability induced by graphene [25].

\subsection{Flexibility and impact resistance}

Mechanical properties such as elasticity and impact resistance in addition to adhesion and corrosion mitigation are important characteristics of polymer coatings. The bending and the impact resistance tests were conducted on epoxy and $\mathrm{E} / \mathrm{G}$ composites coatings in order to evaluate the impact of graphene on the flexibility and impact resistance. Figure 14 shows the bending and impact resistance results for different coatings, where the main bending diameters and the elevations at which the coating fails for five times are reported. These results illustrate that incorporation of graphene reduces the flexibility of the epoxy coating and the degree of reduction increases with graphene loading, which is attributed to the increase in stiffness. In contrast, the addition of graphene enhances the impact resistance of epoxy and here too, the degree of enhancement is proportional to the graphene loading. The observed effects of graphene on the bending and the impact resistance are attributed to the increase in stiffness and toughness of the epoxy composite with graphene loading, which was also reported [26-29], which enhances the resistance to sudden deformation and reduces the elasticity of the epoxy coating.

\section{Conclusions}

Epoxy/graphene composites were prepared using situ prepolymerization approach, spin coated and thermally cured on SS304 substrates. We demonstrated 

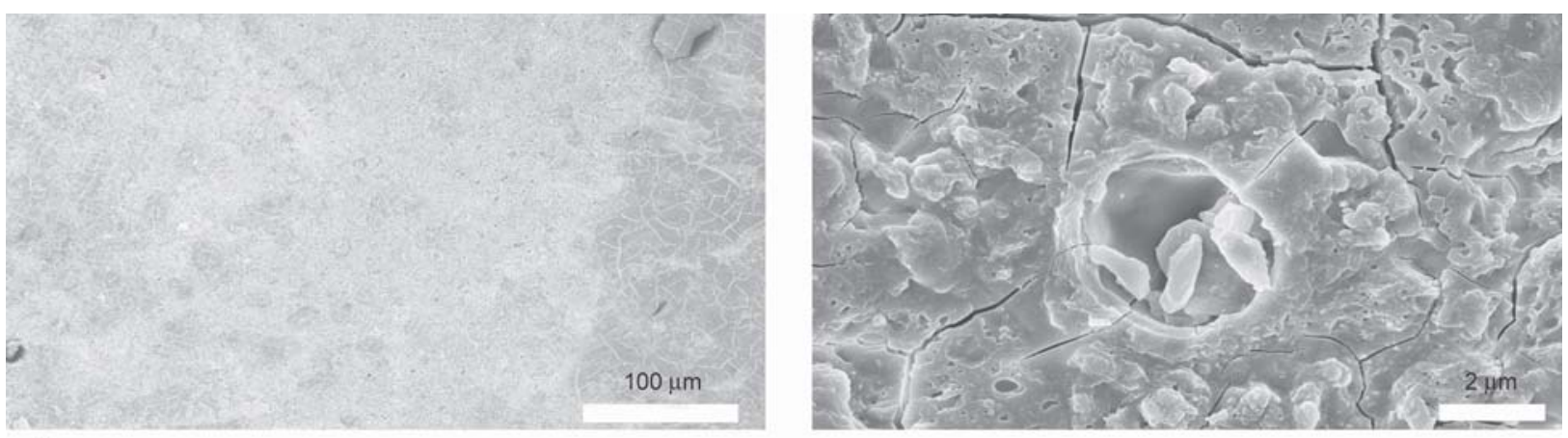

a)
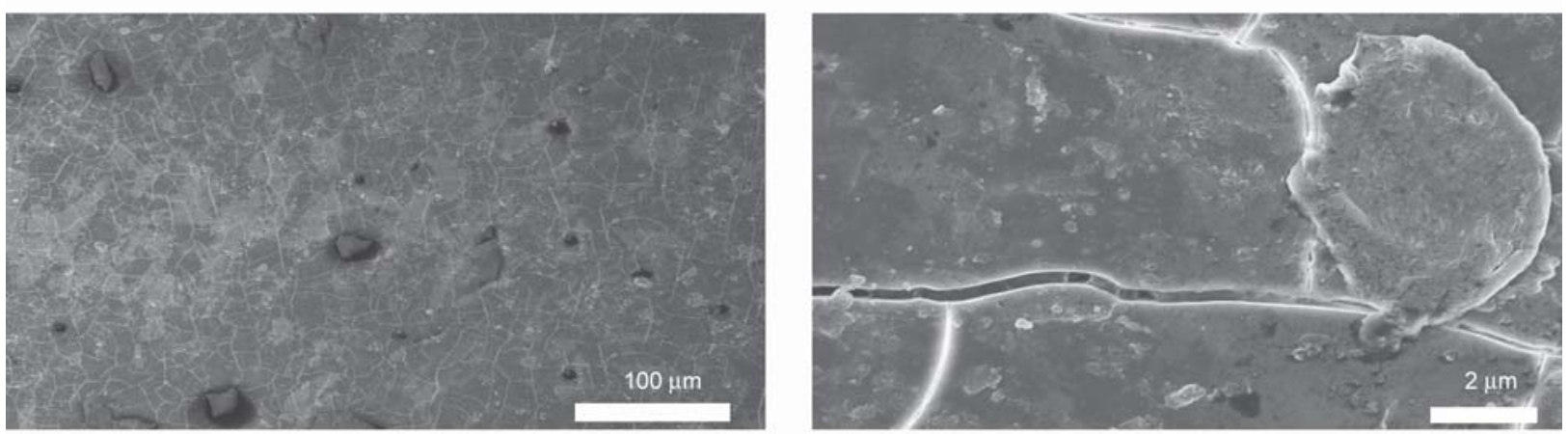

b)
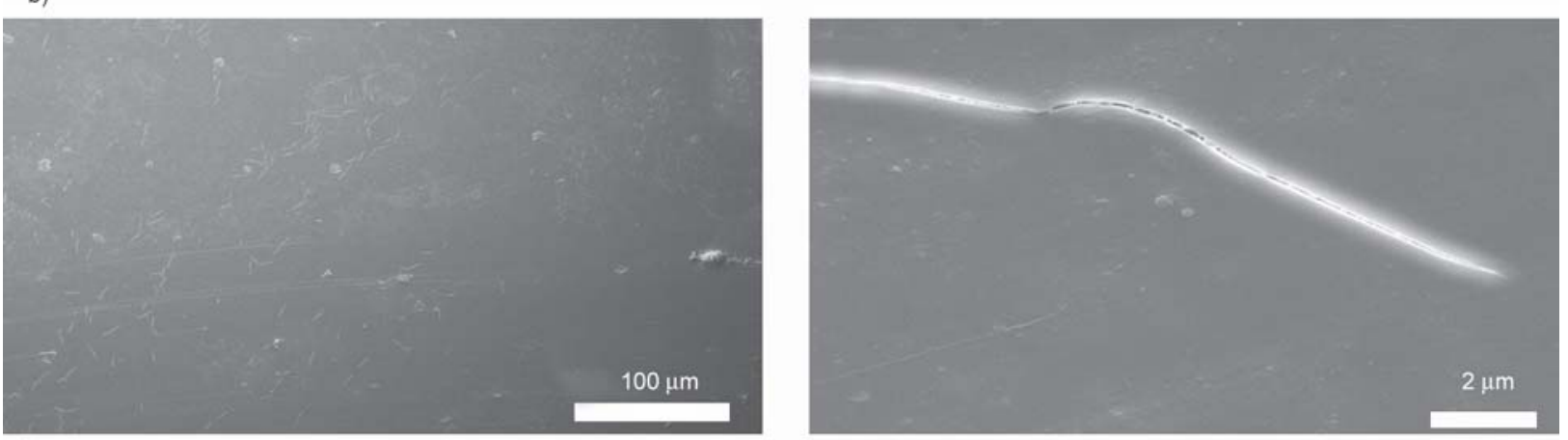

c)

Figure 13. SEM images of post-UV degradation tests of (a) epoxy (b) $E / G_{0.1}$ and (c) $E / G_{0.5}$ coated SS304 substrates after 30 days of exposure to UV and condensation cycles

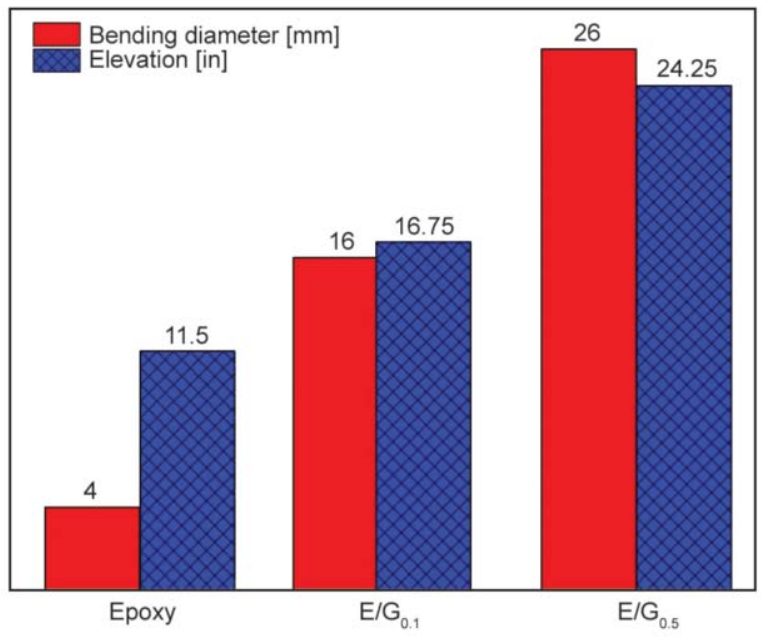

Figure 14. Bending and impact resistance test results for epoxy, $\mathrm{E} / \mathrm{G}_{0.1}$ and $\mathrm{E} / \mathrm{G}_{0.5}$ coatings on $\mathrm{SS} 304$. that the corrosion protection ability of the epoxy is significantly enhanced by incorporation of graphene due to the barrier property of graphene, which shields the corrosive agents from reaching the SS304 substrate. Morover, incorporation of graphene enhances the mechanical properties and impact the thermal properties as well as the adhesion of the epoxy composite to the SS304 substrate. Graphene loading and the degree of dispersion have significant impact on the thermal, and mechanical properties as well as adhesion to the SS304 substrate, the corrosion protection characeteristics and UV stability. Indeed, it is interesting to observe that increasing graphene loading in the epoxy matrix beyond an optimum loading of $0.5 \mathrm{wt} \%$ may attenuate the interface adhesion between coating and the SS304 substrate due to aggre- 
gation of graphene and reduction of the interface area.

\section{Acknowledgements}

The authors would like to acknowledge the financial support of the Petroleum Institute, Abu Dhabi through research project \# 66. The authors also acknowledge the financial support and Mr. Alhumade full scholarship from the Ministry of Education, Saudi Arabia.

\section{References}

[1] Shen G. X., Chen Y. C., Lin C. J.: Corrosion protection of $316 \mathrm{~L}$ stainless steel by a $\mathrm{TiO}_{2}$ nanoparticle coating prepared by sol-gel method. Thin Solid Films, 489, 130-136 (2005).

DOI: $10.1016 /$ j.tsf.2005.05.016

[2] Zheludkevich M. L., Serra R., Montemor M. F., Miranda Salvado I. M., Ferreira M. G. S.: Corrosion protective properties of nanostructured sol-gel hybrid coatings to AA2024-T3. Surface and Coatings Technology, 200, 3084-3094 (2006).

DOI: $10.1016 /$ j.surfcoat.2004.09.007

[3] Moretti G., Guidi F., Grion G.: Tryptamine as a green iron corrosion inhibitor in $0.5 \mathrm{M}$ deaerated sulphuric acid. Corrosion Science, 46, 387-403 (2004).

DOI: 10.1016/S0010-938X(03)00150-1

[4] Gray J., Luan B.: Protective coatings on magnesium and its alloys - A critical review. Journal of Alloys and Compounds, 336, 88-113 (2002). DOI: 10.1016/S0925-8388(01)01899-0

[5] Stratmann M., Feser R., Leng A.: Corrosion protection by organic films. Electrochimica Acta, 39, 1207-1214 (1994).

DOI: 10.1016/0013-4686(94)E0038-2

[6] Mittal V. K., Bera S., Saravanan T., Sumathi S., Krishnan R., Rangarajan S., Velmurugan S., Narasimhan S.: Formation and characterization of bi-layer oxide coating on carbon-steel for improving corrosion resistance. Thin Solid Films, 517, 1672-1676 (2009).

DOI: $10.1016 /$ j.tsf.2008.09.094

[7] Guo S. F., Zhang H. J., Liu Z., Chen W., Xie S. F.: Corrosion resistances of amorphous and crystalline $\mathrm{Zr}$ based alloys in simulated seawater. Electrochemistry Communications, 24, 39-42 (2012).

DOI: $10.1016 /$ j.elecom.2012.08.006

[8] Bellucci F., Nicodemo L., Monetta T., Kloppers M. J., Latanision M. R.: A study of corrosion initiation on polyimide coatings. Corrosion Science, 33, 1203-1226 (1992).

DOI: 10.1016/0010-938X(92)90131-L

[9] Roy D., Simon G. P., Forsyth M., Mardel J.: Towards a better understanding of the cathodic disbondment performance of polyethylene coatings on steel. Advances in Polymer Technology, 21, 44-58 (2002).

DOI: $10.1002 / \mathrm{adv} .10010$
[10] Xu Z., Buehler M. J.: Geometry controls conformation of graphene sheets: Membranes, ribbons, and scrolls. ACS Nano, 4, 3869-3876 (2010).

DOI: $10.1021 / \mathrm{nn} 100575 \mathrm{k}$

[11] Bao C., Song L., Wilkie C., Yuan B., Guo Y., Hu Y., Gong X.: Graphite oxide, graphene, and metal-loaded graphene for fire safety applications of polystyrene. Journal of Materials Chemistry, 22, 16399-16406 (2012). DOI: $10.1039 / \mathrm{C} 2 \mathrm{JM} 32500 \mathrm{D}$

[12] Potts J., Shankar O., Du L., Ruoff R.: Processing-morphology-property relationships and composite theory analysis of reduced graphene oxide/natural rubber nanocomposites. Macromolecules, 45, 6045-6055 (2012). DOI: $10.1021 / \mathrm{ma300706k}$

[13] Li M., Huang X., Wu C., Xu H., Jiang P., Tanaka T.: Fabrication of two-dimensional hybrid sheets by decorating insulating PANI on reduced graphene oxide for polymer nanocomposites with low dielectric loss and high dielectric constant. Journal of Materials Chemistry, 22, 23477-23484 (2012). DOI: $10.1039 / \mathrm{C} 2 \mathrm{JM} 34683 \mathrm{D}$

[14] Longun J., Iroh J.: Nano-graphene/polyimide composites with extremely high rubbery plateau modulus. Carbon, 50, 1823-1832 (2012).

DOI: $10.1016 /$ j.carbon.2011.12.032

[15] Liao K-H., Park Y. T., Abdala A., Macosko C.: Aqueous reduced graphene/thermoplastic polyurethane nanocomposites. Polymer, 54, 4555-4559 (2013).

DOI: $10.1016 /$ j.polymer.2013.06.032

[16] Chang K. C., Hsu C. H., Lu H. I., Ji W. F., Chang C. H., Li W. Y., Chuang T. L., Yeh J. M., Liu W. R., Tsai M. H.: Advanced anticorrosive coatings prepared from electroactive polyimide/graphene nanocomposites with synergistic effects of redox catalytic capability and gas barrier properties. Express Polymer Letters, 8, 243-255 (2014). DOI: $10.3144 /$ expresspolymlett.2014.28

[17] Alhumade H., Abdala A., Yu A., Elkamel A., Simon L.: Corrosion inhibition of copper in sodium chloride solution using polyetherimide/graphene composites. Canadian Journal of Chemical Engineering, 94, 896-904 (2016). DOI: $10.1002 /$ cjce. 22439

[18] Liu S., Gu L., Zhao H., Chen J., Yu H.: Corrosion resistance of graphene-reinforced waterborne epoxy coatings. Journal of Materials Science and Technology, 32, 425-431 (2016). DOI: $10.1016 /$ j.jmst.2015.12.017

[19] Chang C-H., Huang T-C., Peng C-W., Yeh T-C., Lu HI., Hung W-I., Weng C-J., Yang T-I., Yeh J-M.: Novel anticorrosion coatings prepared from polyaniline/ graphene composites. Carbon, 50, 5044-5051 (2012). DOI: $\underline{10.1016 / \text { j.carbon.2012.06.043 }}$ 
[20] Chen Y., Zhang H-B., Huang Y., Jiang Y., Zheng W-G., Yu Z-Z.: Magnetic and electrically conductive epoxy/ graphene/carbonyl iron nanocomposites for efficient electromagnetic interference shielding. Composites Science and Technology, 118, 178-185 (2015).

DOI: 10.1016/j.compscitech.2015.08.023

[21] Wan Y-J., Yang W-H., Yu S-H., Sun R., Wong C-P., Liao W-H.: Covalent polymer functionalization of graphene for improved dielectric properties and thermal stability of epoxy composites. Composites Science and Technology, 122, 27-35 (2016).

DOI: 10.1016/j.compscitech.2015.11.005

[22] Wang F., Drzal L., Qin Y., Huang Z.: Enhancement of fracture toughness, mechanical and thermal properties of rubber/epoxy composites by incorporation of graphene nanoplatelets. Composites Part A: Applied Science and Manufacturing, 87, 10-22 (2016).

DOI: $10.1016 /$ j.compositesa.2016.04.009

[23] Liao K-H., Aoyama S., Abdala A., Macosko C.: Does graphene change $T_{\mathrm{g}}$ of nanocomposites? Macromolecules, 47, 8311-8319 (2014).

DOI: $10.1021 / \mathrm{ma} 501799 \mathrm{z}$

[24] Tang L-C., Wan Y-J., Yan D., Pei Y-B., Zhao L., Li YB., Wu L-B., Jiang J-X, Lai G-Q.: The effect of graphene dispersion on the mechanical properties of graphene/epoxy composites. Carbon, 60, 16-27 (2013). DOI: 10.1016/j.carbon.2013.03.050
[25] Ghasemi-Kahrizsangi A., Neshati J., Shariatpanahi H., Akbarinezhad E.: Improving the UV degradation resistance of epoxy coatings using modified carbon black nanoparticles. Progress in Organic Coatings, 85, 199 207 (2015).

DOI: 10.1016/j.porgcoat.2015.04.011

[26] Wan Y-J., Yang W-H., Yu S-H., Sun R., Wong C-P., Liao W-H.: Covalent polymer functionalization of graphene for improved dielectric properties and thermal stability of epoxy composites. Composites Science and Technology, 122, 27-35 (2016).

DOI: 10.1016/j.compscitech.2015.11.005

[27] Rafiee M., Rafiee J., Wang Z., Song H., Yu Z-Z., Koratkar N.: Enhanced mechanical properties of nanocomposites at low graphene content. ACS Nano, 3, 38843890 (2009).

DOI: $10.1021 / \mathrm{nn} 9010472$

[28] Chandrasekaran S., Sato N., Tölle F., Mülhaupt R., Fiedler B., Schulte K.: Fracture toughness and failure mechanism of graphene based epoxy composites. Composites Science and Technology, 97, 90-99 (2014). DOI: $10.1016 /$ j.compscitech.2014.03.014

[29] Bortz D. R., Heras E. G., Martin-Gullon I.: Impressive fatigue life and fracture toughness improvements in graphene oxide/epoxy composites. Macromolecules, 45, 238-245 (2011). DOI: $\underline{10.1021 / \mathrm{ma} 201563 \mathrm{k}}$ 